\title{
PEMANASAN SEBAGAI KATALISATOR BAHAN KOAGULAN TAWAS DAN KAPUR DALAM PENGOLAHAN AIR SUNGAI DI DESA PENJARATAN KECAMATAN PELAIHARI KABUPATEN TANAH LAUT TAHUN 2016
}

\author{
Roby Astuti, Maharso, Sulaiman Hamzani \\ Poltekkes Kemenkes Banjarmasin Jurusan Kesehatan Lingkungan \\ Jl. H. Mistar Ckokrokusumo No. 1A Banjarbaru Kalimantan Selatan 70714 \\ E-mail: robbyastuty92@gmail.com
}

\begin{abstract}
Heating As The Catalyst Of Alum And Lime Coagulant Materials In The River Water Processing In Penjaratan Village Pelaihari District Tanah Laut Regency In 2016. Water is a basic need in the human's life. Therefore, water must be available in adequate quantity and quality such physical quality especially the turbidity at river water in. This study aims to find out the heat value as the catalyst of alum and lime coagulant materials in reducing the river water turbidity. The research method used is jar test, quasieksperiment designs in nature. Dependent variables in this study are turbidity and $\mathrm{pH}$, independent variables are alum and lime doses and heating solution temperature. Data analysis is using Two-Way Anova statistical test.The study result in April 2016 shows there is a difference between catalyst without heating with early turbidity heating is $65.7 \mathrm{NTU}$ and turbidity with processing without heating at settling time variation 5 minutes 20.7 NTU, 10 minutes $18.32 \mathrm{NTU}$ and 15 minutes $17.45 \mathrm{NTU}$ while with heating at settling time variation 5 minutes 14.27 NTU, 10 minutes 13.6 NTU and 15 minutes 13.1 NTU. The statistical test result shows the p-value in the catalyst is $<0.05$ (there is a significant difference), while in the time and catalyst with time $\mathrm{p}$-value $>0.05$ (there is no significant difference).
\end{abstract}

Keyword: Catalyst; Alum; Lime; Turbidity

Abstrak: Pemanasan Sebagai Katalisator Bahan Koagulan Tawas Dan Kapur Dalam Pengolahan Air Sungai Di Desa Penjaratan Kecamatan Pelaihari Kabupaten Tanah Laut Tahun 2016. Air merupakan kebutuhan dasar bagi kehidupan manusia. Oleh karena itu, air harus tersedia dalam kuantitas dan kualitas yang memadai seperti kualitas fisik khususnya kekeruhan pada air sungai. Penelitian ini bertujuan untuk mengetahui kemampuan pemanasan sebagai katalisator bahan koagulan tawas dan kapur dalam menurunkan kekeruhan air sungai. Metode penelitian ini menggunakan jar test, bersifat eksperimen-semu. Variabel terikat pada penelitian ini adalah kekeruhan dan $\mathrm{pH}$, variabel bebasnya adalah dosis tawas dan kapur, suhu larutan pemanasan. Analisis data menggunakan statistik uji Two Way Anova. Hasil penelitian pada bulan April 2016 menunjukan bahwa ada perbedaan antara katalisator tanpa pemanasan dengan pemanasan nilai kekeruhan awal sebesar 65,7 NTU dan nilai kekeruhan sesudah pengolahan tanpa pemanasan pada variasi waktu pengendapan 5 menit 20,7 NTU, 10 menit 18,32 NTU, dan 15 menit 17,45 NTU sedangkan dengan pemanasan pada variasi waktu pengendapan 5 menit 14,27 NTU, 10 menit 13,6 NTU dan 15 menit 13,1 NTU. Hasil uji statistik menunjukkan nilai $p$-value pada katalisator adalah $<0,05$ (ada pebedaan) sedangkan pada waktu dan katalisator dengan waktu nilai $p$-value $>0,05$ (tidak ada pebedaan).

Kata kunci: Katalisator; Tawas; Kapur; Kekeruhan.

\section{PENDAHULUAN}

Air merupakan salah satu

komponen yang paling dekat dengan manusia yang menjadi kebutuhan dasar bagi kehidupan manusia. Oleh karena hal tersebut air harus tersedia dalam kuantitas dan kualitas yang memadai dalam kehidupan sehari-hari(1).

Air adalah salah satu dari materi yang dibutuhkan untuk menjaga kelangsungan hidup mahluk hidup dan juga menjadi salah satu sumber penyebab dari penyakit yang menyerang manusia. 
Hal utama yang perlu diperhatikan dalam mengolah air yang akan dikonsumsi adalah menyediakan air yang aman dikonsumsi dari segi kesehatan. Sumber air, baik air permukaan maupun air tanah, akan terus mengalami peningkatan kontaminasi pencemar disebabkan meningkatnya aktivitas pertanian dan industri. Air hasil produksi yang diharapkan konsumen adalah air yang bebas dari warna, kekeruhan, rasa, bau, nitrat, ion logam berbahaya dan berbagai macam senyawa kimia organik seperti pestisida dan senyawa terhalogenasi. Permasalahan kesehatan yang berkaitan dengan kontaminan tersebut meliputi kangker, gangguan pada bayi yang lahir, kerusakan jaringan saraf pusat, penyakit jantung(2).

Penyakit-penyakit yang berhubungan dengan air dan mekanisme cara penularan adalah infeksi melalui alat pencernaan seperti diare pada anak-anak, infeksi melalui kulit dan mata seperti scabies dan trachoma dan penularan melalui binatang pengerat seperti pada penyakit leptospirosis(3).

Menurut PP No. 35 Tahun 1991 sungai adalah tepat-tempat dan wadahwadah serta jaringan pengaliran air mulai dari mata air sampai muara dengan dibatasi kanan dan kirinya serta sepanjang pengalirannya oleh garis sempadan. Sungai sebagai sumber air merupakan salah satu sumber daya alam yang mempunyai fungsi serbaguna bagi kehidupan dan penghidupan manusia.

Sungai memiliki peranan yang sangat penting dalam pemenuhan kebutuhan bagi masyarakat di Kabupaten Tanah Laut, Kecamatan Pelaihari khususnya Desa Penjaratan yang tinggal di pinggir sungai tersebut, digunakan sebagai tempat mandi dan mencuci, membuang sampah serta sebagai tempat pembuangan tinja, dan jika terjadi hujan maka air sungai lebih keruh dari biasanya dan secara kesehatan tidak memenuhi standar fisik, alternatif pengolahan yang digunakan masyarakat yaitu mengendapkan air untuk mengurangi kekeruhan air sungai tersebut.
Untuk memenuhi kebutuhan air bersih bagi masyarakat maka harus dilakukan pengolahan air sungai dengan metode pengolahan secara fisik, salah satunya koagulan menggunakan bahan tawas dan kapur. Sebab air sungai tersebut menjadi kebutuhan yang sangat penting bagi masyarakat karena sumber air bersih seperti PDAM belum ada di desa tersebut.

Berdasarkan penelitian Muhammad Fahrurrazi 2008, diperoleh hasil bahwa mengunakan variasi koagulan tawas dan kapur $0,2 \%$ dengan hasil terbaik yaitu pada dosis tawas $3,5 \mathrm{ml} / \mathrm{L}$ yang mampu menurunkan nilai kekeruhan dari 50 NTU menjadi 15 NTU nilai pH 7,1 dan berdasarkan dari penelitian Baba Yuga 2015 diperoleh hasil terbaik yaitu pada dosis tawas $8 \mathrm{ml} / \mathrm{L}$ dan kapur $4 \mathrm{ml} / \mathrm{L}$, yang mampu menurunkan nilai kekeruhan dari 95 NTU menjadi 22,6 $(76,23 \%)$ dan $\mathrm{pH} 6,84$. Jadi semakin kekeruh air sungai maka semakin tinggi dosis yang diperlukan.

Proses koagulasi adalah proses yang ditambahkan koagulan, yaitu bahan kimia yang dapat mempercepat proses pengendapan partikel dan menurunkan kadar karbonat dalam air. Proses koagulasi merupakan proses penggumpalan partikel yang larut dalam air (4).

Persenyawaan Aluminium Sulfat $\left(\mathrm{Al}_{2}\left(\mathrm{SO}_{4}\right)_{3}\right)$ atau sering disebut tawas adalah suatu jenis koagulan yang sangat populer secara luas digunakan, sudah dikenal bangsa Mesir pada awal tahun 2000 SM. Alum atau tawas sebagai penjernih air mulai diproduksi oleh pabrik pada awal abad 15. Alum atau tawas merupakan bahan koagulan, yang paling banyak digunkan karena bahan ini paling ekonomis (murah), mudah didapatkan di pasaran serta mudah penyimpanannya(6).

Alum kalium sangat larut dalam air panas, sehingga ketika setelah penambahan $\mathrm{H}_{2} \mathrm{SO} 4$ yang membentuk endapan dan kemudian dipanaskan, pemanasan sebaiknya dilakukan pada suhu $60-80^{\circ} \mathrm{C}$ untuk menguapkan airnya dan suhu pemanasan tidak boleh lebih 
dari $80^{\circ} \mathrm{C}$ karena tawas akan larut dalam air mendidih. Ketika kristalin alum kalium dipanas kanterjadi pemisahan secara kimia, dan sebagian garam yang terdehidrasi terlarut dalam air. Pada proses penguapan selama 10 menit dan didinginkan akan terbentuk Kristal dari $\mathrm{KAl}\left(\mathrm{SO}_{4}\right)_{2} .12 \mathrm{H}_{2} \mathrm{O}(7)$.

Secara umum peneliti ini bertujuan untuk mengetahui kemampuan pemanasan sebagai katalisator bahan koagulan tawas dan kapur dalam menurunkan kekeruhan air sungai di Desa Penjaratan Kecamatan Pelaihari Kabupaten Tanah Laut, mengetahui nilai kekeruhan dan $\mathrm{pH}$ air sungai di Desa Penjaratan Kecamatan Pelaihari Kabupaten Tanah Laut, mengetahui perbedaan tingkat kekeruhan dan $\mathrm{pH}$ sebelum dan sesudah pengolahan tanpa pemanasan bahan koagulan tawas dan kapur yang ditambahkan kedalam air sungai sebagai pembanding, mengetahui perbedaan tingkat kekeruhan dan $\mathrm{pH}$ sebelum dan sesudah pengolahan dengan pemanasan sebagai katalisator bahan koagulan tawas dan kapur yang ditambahkan kedalam air sungai dan mengetahui perbedaan katalisator dengan waktu pengendapan terhadap nilai kekeruhan.

\section{BAHAN DAN CARA PENELITIAN}

Rancangan penelitian ini adalah eksperimen-semu yaitu non-equivalent control group (38), karena melakukan uji coba pengolahan air sungai parameter kekeruhan dan $\mathrm{pH}$ menggunakan penambahan dosis optimum koagulan tawas dan kapur tanpa pemanasan dan dengan pemanasan sebagai katalisator. Adapun desain penelitian dapat digambarkan sebagai berikut. Populasi penelitian adalah semua air yang mengalir disepanjang sungai yang melintasi Desa Penjaratan Kecamatan Pelaihari Kabupaten Tanah Laut. Yang menjadi penelitian ini adalah variabel bebas adalah dosis tawas dan kapur tanpa pemanasan dan pemanasan. Variabel terikat adalah kualitas air yang dinyatakan dalam variabel kekeruhan dan $\mathrm{pH}$ akibat penambahan larutan tawas dan kapur. Metode pengumpul data yaitu data primer yaitu air baku, kekeruhan dan $\mathrm{pH}$ air sungai. Data primer diperoleh dari hasil percobaan penambahan dosis optimum yang menggunakan tanpa pemanasan dengan pemanasan terhadap air sampel yaitu pengukuran nilai $\mathrm{pH}$ dan kekeruhan air sampel di laboratorium. Pengolahan data menggunakan uji statistik "Anova Two Way Analisys of Variance".

\section{HASIL PENELITIAN DAN PEMBAHASAN}

Hasil pemeriksaan kualitas air bersih yaitu nilai kekeruhan pada air sungai di Desa Penjaratan Kecamatan Pelaihari Kabupaten Tanah Laut yang dilakukan pada bulan April tahun 2016 di laboratorium Kesehatan Lingkungan Banjarbaru adalah berikut :

Tabel 1. Pengukuran Nilai Kekeruhan Pada Sampel Air Sungai Sebelum Pengolahan

$\begin{array}{cc}\text { Kode Sampel Kekeruhan NTU } & \begin{array}{c}\text { Nilai Maksimum Yang } \\ \text { Diperbolehkan NTU }\end{array}\end{array}$

\begin{tabular}{ccc}
\hline Sebelum & 65,7 & 25 \\
\hline
\end{tabular}

Sumber: Data Penelitian (2016)

Dari tabel 1. menunjukkan bahwa pengukuran nilai kekeruhan pada air sungai sebelum pengolahan sebesar 65,7 NTU yaitu melebihi standar baku mutu persyaratan kekeruhan kualitas air bersih yaitu $<25$ NTU. Untuk perbedaan penurunan nilai kekeruhan pada variasi waktu pengendapan 5 menit dapat dilihat pada tabel 2. sebagai berikut: 
Tabel 2. Perbedaan Penurunan Kekeruhan Pada Variasi Waktu Pengendapan 5 Menit

\begin{tabular}{cccccc}
\hline $\begin{array}{c}\text { Variasi waktu } \\
\text { Pengendapan } \\
\text { (menit) }\end{array}$ & $\begin{array}{c}\text { Pengulanga } \\
\text { n }\end{array}$ & $\begin{array}{c}\text { Tanpa Pemanasan } \\
\text { Kekeruhan } \\
(\mathrm{NTU})\end{array}$ & $\begin{array}{c}\text { Penurunan } \\
(\%)\end{array}$ & $\begin{array}{c}\text { Dengan Pemanasan } \\
\text { Kekeruhan } \\
(\mathrm{NTU})\end{array}$ & $\begin{array}{c}\text { Penurunan } \\
(\%)\end{array}$ \\
\hline 5 menit & 1 & 19,9 & 69.71 & 14,1 & 78,54 \\
5 menit & 2 & 19,1 & 70,93 & 13,3 & 79,76 \\
5 menit & 3 & 23,1 & 64,84 & 17,7 & 73,06 \\
5 menit & 4 & 20,7 & 68,49 & 12,0 & 81,74 \\
Rata-rata & - & 20,7 & 68,49 & 14,27 & 78,27 \\
\hline
\end{tabular}

Sumber: Data Penelitian (2016)

Berdasarkan tabel 2 menunjukan bahwa pengaruh semua perlakuan variasi waktu pengendapan 5 menit mampu menurunkan nilai kekeruhan baik terhadap perlakuan tanpa pemanasan maupun terdahap perlakuan dengan pemanasan, sedangkan nilai $\mathrm{pH}$ normal sebelum maupun sesudah perlakuan. Untuk perbedaan penurunan nilai kekeruhan pada variasi waktu pengendapan 10 menit dapat dilihat pada tabel 3. sebagai berikut:

Tabel 3. Perbedaan Penurunan Kekeruhan Pada Variasi Waktu Pengendapan 10 Menit

\begin{tabular}{cccccc}
\hline $\begin{array}{c}\text { Variasi waktu } \\
\begin{array}{c}\text { Pengendapan } \\
\text { (menit) }\end{array}\end{array}$ & Pengulangan & $\begin{array}{c}\text { Tanpa Pemanasan } \\
\text { Kekeruhan } \\
\text { (NTU) }\end{array}$ & $\begin{array}{c}\text { Penurunan } \\
(\%)\end{array}$ & $\begin{array}{c}\text { Dengan Pemanasan } \\
\text { Kekeruhan } \\
\text { (NTU) }\end{array}$ & $\begin{array}{c}\text { Penurunan } \\
(\%)\end{array}$ \\
\hline 10 menit & 1 & 16,5 & 74,89 & 13,4 & 79,60 \\
10 menit & 2 & 17,4 & 73,55 & 13,1 & 80,06 \\
10 menit & 3 & 21,0 & 68,04 & 16,6 & 74,73 \\
10 menit & 4 & 18,4 & 71,99 & 11,5 & 82,50 \\
Rata-rata & - & 18,32 & 72,11 & 13,6 & 79,22 \\
\hline
\end{tabular}

Sumber: Data Penelitian (2016)

Dari tabel 3 diatas menunjukan bahwa pengaruh semua perlakuan variasi waktu pengendapan 10 menit mampu menurunkan nilai kekeruhan baik terhadap perlakuan tanpa pemanasan maupun terdahap perlakuan dengan pemanasan.

Untuk perbedaan penurunan nilai kekeruhan pada variasi waktu pengendapan 15 menit dapat dilihat pada tabel 4 sebagai berikut:

Tabel 4. Perbedaan Penurunan Kekeruhan Pada Variasi Waktu Pengendapan 15 Menit

\begin{tabular}{cccccc}
\hline $\begin{array}{c}\text { Variasi waktu } \\
\text { Pengendapan } \\
\text { (menit) }\end{array}$ & Pengulangan & $\begin{array}{c}\text { Tanpa Pemanasan } \\
\text { Kekeruhan } \\
\text { (NTU) }\end{array}$ & $\begin{array}{c}\text { Penurunan } \\
(\%)\end{array}$ & $\begin{array}{c}\text { Dengan Pemanasan } \\
\text { Keruhan } \\
(\text { NTU) }\end{array}$ & $\begin{array}{c}\text { Penurunan } \\
(\%)\end{array}$ \\
\hline 15 menit & 1 & 15,5 & 76.41 & 12,7 & 80,67 \\
15 menit & 2 & 16,6 & 74,73 & 12,7 & 80,67 \\
15 menit & 3 & 20,7 & 68,49 & 15,8 & 75,95 \\
15 menit & 4 & 17,0 & 74,12 & 11,2 & 82,95 \\
Rata-rata & - & 17,45 & 73,44 & 13,1 & 80,06 \\
\hline
\end{tabular}

Sumber: Data Penelitian (2016) 
Dari tabel 4 diatas menunjukan bahwa pengaruh semua perlakuan variasi waktu pengendapan 15 menit mampu menurunkan nilai kekeruhan baik terhadap perlakuan tanpa pemanasan maupun terdahap perlakuan dengan pemanasan, sedangkan nilai $\mathrm{pH}$ normal sebelum maupun sesudah perlakuan.

Asumsi uji anova antara lain data harus normalitas, setelah dilakukan uji normalitas, pada kolom shapiro-wilk didapatkan nilai $\mathrm{p}=0,382$ artinya data normal, sehingga uji anova bisa dilakukan untuk uji bivariat.

Data hasil analisis statistik menggunakan uji Anova Two Way Analisys of Variance untuk Perbedaan Nilai Kekeruhan Menurut Katalisator Dan Waktu Pengendapan dapat dilihat pada tabel 5 sebagai berikut:

Tabel 5. Kemaknaan Perbedaan Nilai Kekeruhan Menurut Katalisator Dan Waktu

Pengendapan

\begin{tabular}{cccc}
\hline No & Variasi & Nilai $p$-value & Kemaknaan \\
\hline 1 & Katalisator & 0.000 & Bermakna \\
2 & Waktu & 0.125 & Tidak Bermakna \\
3 & Katalisator*Waktu & 0.676 & Tidak Bermakna \\
\hline
\end{tabular}

Sumber: Data Penelitian (2016)

Berdasarkan Tabel 5 hasil uji statistik menunjukkan nilai $p$-value pada katalisator adalah $0.000(<0,05)$ maka Ho ditolak dan Ha diterima artinya ada perbedaan antara perlakuan pemanasan sebagai katalisator dan tanpa pemanasan menggunakan koagulan tawas dan kapur, sedangkan pada variabel waktu nilai $p$ value $0.125(>0,05)$ maka Ho diterima dan Ha ditolak artinya tidak ada perbedaan pada variabel waktu terhadap nilai kekeruhan, untuk interaksi variabel katalisator dengan waktu nilai $p$-value $0.676(>0,05)$ maka Ho diterima dan Ha ditolak artinya tidak ada pebedaan/pengaruh katalisator dengan waktu terhadap nilai kekeruhan.

\section{PEMBAHASAN}

Berdasarkan tabel 5. yang merupakan tampilan hasil uji laboratorium sebelum pengolahan nilai kekeruhan dan $\mathrm{pH}$ air sungai di Desa Penjaratan Kecamatan Pelaihari Kabupaten Tanah Laut bulan April tahun 2016 adalah sebesar 65,7 NTU, sehingga tidak memenuhi syarat jika dibandingkan dengan standar parameter kekeruhan $(25$ NTU) menurut peraturan persyaratan kualitas air bersih yang ditetapakan oleh
Permenkes RI No. 416/MENKES/PER/ IX/1990.

Air yang dipergunakan untuk keperluan sehari-hari harus memenuhi persyaratan kesehatan karena air merupakan suatu sarana utama untuk meningkatkan derajat kesehatan masyarakat, karena air merupakan salah satu media dari berbagai penularan penyakit. Cara pengolahan air dari berbagai zat pengotor salah satunya pada komponen turbidity (kekeruhan) adalah koagulasi, pengendapan dan filtrasi. Penurunan nilai kekeruhan dapat terjadi karena adanyan proses koagulasi untuk menggabungkan partikel kecil menjadi agregat yang lebih besar. Proses penambahan bahan kimia ke dalam air dan proses untuk menggabungkan partikel koloid dan partikel kecil menjadi agregat yang lebih besar dan dapat mengadsorb material organik terlarut ke permukaan agregat sehingga dapat mengendap. Selama ini telah banyak dilakukan penelitian untuk menjernihkan air melalui berbagai jenis koagulan alternatif. Jenis koagulan yang sering digunakan di antaranya adalah; alum (tawas) dan kapur. Tawas akan bereaksi dengan hidroksida dan akan mengendap sebagai flok AI $(\mathrm{OH})$ yang 
mengurung koloid dan membawanya kebawah sehingga terjadi pengendapan. Reaksi antara hidroksida dalam air dengan ion alumunium meakibatkan penurunan alkalinitas, jika alkalinitas air secara alami tidak cukup untuk bereaksi dengan alum yang ditambahkan, maka dapat ditambahkan alkalinitas dalam bentuk kapur hidrasi $\mathrm{Ca}(\mathrm{OH})_{2}$. Larutan alum dalam air menghasilkan: Al2(SO4)3.18H2O -----> 2 AI3 + 3 SO42- + $18 \mathrm{H} 20$. Ion-ion hidroksida hasil dari ionisasi air : $\mathrm{H} 2 \mathrm{O}----->\mathrm{H}++\mathrm{OH}-$. Ion-ion alumunium $(\mathrm{AI} 3+)$ kemudian bereaksi : 2 AI3+ -----> + 6 OH- -----> 2 AI $(\mathrm{OH}) 2$.

Proses koagulasi yang dapat terjadi karena pengaruh pemanasan, bergeraknya partikel koloid dalam medan listrik dapat menyebabkan koagulasi karena endapan pada salah satu elektrode semakin lama semakin pekat dan akhirnya membentuk gumpalan. Penggunaan katalisator (dengan pemanasan) mampu membuktikan bahwa alum kalium sangat larut dalam air panas, sehingga lebih mempercepat proses pengendapan dalam menurunkan nilai kekeruhan, untuk pemanasan sebaiknya dilakukan pada suhu $60-80^{\circ} \mathrm{C}$ dan suhu pemanasan tidak boleh lebih dari $80^{\circ} \mathrm{C}$ karena tawas akan larut dalam air mendidih

Proses flokulasi merupakan proses pengadukan cepat yang kemudian dilanjutkan dengan pengadukan lambat selama 20 hingga 30 menit yang menyebabkan bertumbukannya kumpulan-kumpulan partikel kecil yang akan membentuk partikel-partikel yang lebih besar sehingga dapat mengendap dengan sendirinya oleh gaya gravitasi.

Sedimentasi merupakan proses pengendapan partikel-partikel padat yang tersuspensi dalam cairan/zat cair dengan menggunakan pengaruh gravitasi. Proses pengendapan dengan cara gravitasi untuk mengendapkan partikel-partikel yang tersuspensi yang lebih berat dari pada air, ini yang pling sering digunakan dalam pengolahan air

Berdasarkan uji statistik pada katalisator menunjukkan bahwa ada perbedaan secara nyata ( $p$-value $<0,05$ ). Artinya, ada perbedaan penurunan nilai kekeruhan akibat pemanasan sebagai katalisator dan tanpa pemanasan menggunakan koagulan tawas dan kapur. Sedangkan hasil uji statistik untuk variabel waktu pengendapan menunjukkan tidak ada perbedaan secara nyata ( $p$-value $>0,05$ ) yang artinya tidak ada perbedaan waktu pengendapan terhadap penurunan nilai kekeruhan, karena waktu pengendapan yang digunakan terlalau singkat sehingga penurunan tidak terlihat berbeda secara nyata, maka dapat disimpulkan bahwa waktu pengendapan yang digunakan adalah pada waktu pengendapan 5 menit, untuk interaksi variabel katalisator dengan waktu pengendapan menunjukkan bahwa tidak ada perbedaan secara nyata ( $p$-value $<0,05$ ). Artinya tidak ada pengaruh katalisator dengan variasi waktu pengendapan terhadap penurunan nilai kekeruhan, karena ratarata nilai kekeruhan untuk tiap katalisator berbeda namun sama pada tiap perlakuan waktu pengendapan).

\section{KESIMPULAN DAN SARAN}

Untuk nilai kekeruhan sebelum pengolahan pada air sungai di Desa Penjaratan Kecamatan Pelaihari Kabupaten Tanah Laut 2016 dengan hasil 65,7 NTU. Untuk nilai kekeruhan sesudah pengolahan tanpa pemanasan pada variasi waktu pengendapan 5 menit 20,7 NTU (penurunan 68,49\%), variasi waktu pengendapan 10 menit 18,32 NTU (penurunan $72,11 \%$ ) dan pada variasi waktu pengendapan 15 menit 17,45 NTU (penurunan73,44\%). Untuk perbedaan tingkat kekeruhan dan $\mathrm{pH}$ sesudah pengolahan dengan pemanasan pada variasi waktu pengendapan 5 menit 14,27 NTU (penurunan 78,27\%), variasi waktu pengendapan 10 menit 13,6 NTU (penurunan $79,22 \%$ ) dan pada variasi waktu pengendapan15 menit 13,1 NTU (penurunan $80,06 \%$ ). Untuk perbedaan pemanasan dengan pengaruh waktu pengendapan terhadap nilai kekeruhan dengan uji statistik menunjukkan nilai $p$ value pada katalisator adalah $<0,05$ sehingga dapat disimpulkan bahwa ada pebedaan yang bermakna sedangkan 
pada waktu dan katalisator dengan waktu nilai $p$-value $>0,05$ sehingga dapat disimpulkan bahwa tidak ada pebedaan yang bermakna.

Dapat disarankan bagi masyarakat di desa Penjaratan agar dapat menggunakan katalisator dengan pemanasan $\pm 60^{\circ} \mathrm{C}$ dengan dosis $6,6 \mathrm{ml} / \mathrm{L}$ (tawas + kapur) dalam $500 \mathrm{ml} / \mathrm{L}$ air baku untuk menurunkan nilai kekeruhan sebesar $\pm 65,7$ NTU yang ada pada air sungai.

\section{KEPUSTAKAAN}

1. Siombo, M. R. 2012. Hukum Lingkungan dan Pelaksanaan Pembangunan Berkelanjutan Di Indinesia PT Gramedia Pustaka Utama, Jakarta.

2. Sawyer, C. N. 1994. Chemistry For Environmental Engineering, Fourth Edition. McGraw- Hill, Inc. Singapore.

3. Candra, B. 2007. Pengantar Kesehatan Lingkungan. Penerbit Buku Kedokteran EGC. Jakarta.

4. Subarnas, N. 2007. Terampil Berkreasi. PT Grafindo Media Pratama. Jakarta.

5. Budi, S. 2006. Penurunan Fosfat dengan Penambahan Kapur (Lime), Tawas dan Filtrasi Zeolit pada Limbah Cair (Studi Kasus RS Bethesda Yogyakarta). Tesis Magister. UNDIP. Semarang.

6. Indrawati, D. V. 2014. Pembuatan Tawas dari Aluminium Foil. Jakarta

7. Subarnas, N. 2007. Terampil Berkreasi. PT Grafindo Media Pratama. Jakarta. 
